\title{
Comparative Analysis of Axial Map Drawing Methods: Elazı̆̆ Application
}

\author{
Emrah Şıkoğlu1 $\odot$ \\ 1 Asst. Prof. Dr. Faculty of Humanities and Social Sciences, Department of Geography, Firat University, Elazığ, Turkey \\ (Principal contact for editorial correspondence.) Email: emrahskoglu@firat.edu.tr
}

\begin{abstract}
Purpose

There are three basic methods used for creating axial maps in Space Syntax studies. Manual drawing is the first and most grounded method. The second method is the production of automatic axial maps with a tool, known as the Axial Map in the Depth Map program. The third and most modern method is the use of lines named Road Center Line (RCL). The primary goal of this study is to reveal the relationship between manual drawing, which is the first method used in creating axial maps and still regarded as the most reliable one, and other methods used in drawing axial maps. The other purposes of the study are analysing the features of methods used in creating axial maps, presenting the advantages and disadvantages of these methods, and comparing the methods. Accurately analysing wide spaces such as urban settlements and supporting Space Syntax studies for preventing drawing differences resulting from users in manual drawings are the other goals of this study.

Design/Methodology/Approach

The above mentioned three methods used for creating axial maps are compared in the study in terms of the period, morphological similarity, and analysis results. Analyses are carried out in Depth MapX and the MapInfo program is used for arrangements.

\section{Findings}

The manual drawing method is the most time consuming one while the RCL maps technique is the least time-consuming. Automatic drawing creates the axial maps based on the very same rules, which makes it the closest technique to the traditional drawing method in terms of textural similarity. However, it is believed that both automatic drawing and RCL need improvement.

\section{Research Limitations/Implications}

Manuel Drawing takes a very long time. Therefore, only one application city (Elazig) could be selected in the study.

Social/Practical Implications

The practitioner who wants to decide which of these methods to choose can decide this by looking at this study. He/she can also have an idea of what to pay attention to when using the methods.

Originality/Value

In this study, three different axial map-drawing techniques were applied to a city. Besides, for the first time, three drawing techniques were compared and discussed in this study.
\end{abstract}

Keywords: Axial map, Elazığ, road center line, space syntax, space syntax drawing methods 


\section{INTRODUCTION}

\section{Motivation}

To better understand the urban space, space syntax gives an effective way to measure the configuration (Long, Baran, and Moore, 2007, p. 2). Space Syntax analysis starts with the representation of urban texture. Space Syntax analysis is a method created for understanding the social logic that forms an urban texture; in other words, it aims at studying the potential of physical space in terms of gathering people according to the movement it involves (Çil, 2008, p.283). The goal of this analysis is to form a hierarchy of streets in a settlement from the most frequently used open spaces to the least used ones. The most frequently used streets are called "integrated" while the least used ones are called "segregated". At the end of the analysis, a new map encoded with colors ordered from the most integrated to the most segregated axis is obtained (Çil, 2006, p.224).

Axial maps are the basis of settlement spaces; they indicate the longest visibility distance of a walker on the move in a settlement when he looks around. These maps are formed by drawing the longest and shortest lines through all of the public spaces in a settlement (Özkan Özbek, 2007, p.62). Axial maps are based on the smallest set of straight axial (visual) lines that cover the urban street network. It is possible to subsequently transform axial maps into connectivity graphs, in which the axial lines and the intersections between lines look like the graph's nodes and links, respectively. After that step, the centrality of each axial line within the network is computed according to the graph connectivity attributes (Omer et al., 2017, p.100.4). The concept of axial line is the longest line drawn through an arbitrary point in the spatial configuration (Turner et al., 2005, p.426). An axial map can be defined as the minimal set of axial lines such that the set taken together fully surveils the system; on the other hand, every axial line that may connect two otherwise-unconnected lines is included (Turner et al., 2005, p.428).

Axial maps that are used as base maps in the analyses of both enclosed and urban spaces in the Space Syntax method are represented with lines in the system. There are three basic methods used in creating axial maps. Manual drawing is the first and most grounded method. The second method is the automatic axial maps produced with the tool, known as the Axial Map in Depth Map program. The third and most modern method is the use of lines named Road Center Line (RCL).

There are two important reasons for diversity in axial map-drawing techniques. Firstly, it becomes easier to analyze urban spaces with the Space Syntax technique. Secondly, the method prevents any kind of mistakes in drawing resulting from the viewpoints of two different users that draw the same space; in other words, it unifies the drawings.

The basic motivation of the study is to evaluate the ways of using the three different methods used for drawing the axial map, to compare them, and determine the advantages and disadvantages of methods. 


\section{Purpose and Method}

Firstly, it is important to mention that the study focuses on the methods used for open spaces rather than enclosed ones. The primary goal of this study is to analyze the relationship between manual drawing, which is the first method used in creating axial maps, and other methods. Analyzing wide spaces such as urban settlements, supporting Space Syntax studies for preventing drawing differences resulting from different users in manual drawings are the other purposes of this study. "Level of the similarity between the analyses results of automatically drawn axial map and RCL maps and analyses results of manual drawing" and "The level of overlap between the results of these techniques and the actual space" are the other concerns of this study.

These three methods used in creating axial maps are compared in terms of method, time, and morphological similarity in the scope of the analysis result of this study. Morphological similarity and analysis results of automatically created axial maps and RCL maps will be compared to Manual Drawing which is regarded as the best current method.

The city of Elazığ in the Eastern Anatolia Region, Turkey, was chosen as the environment for comparing these techniques. There are three basic reasons why this city was preferred; firstly, the author of this study is familiar with the city. Secondly, it was easier to make reliable and consistent field observations.

The first step of this study was to draw a manual axial map of Elazığ. Routes of the study field were determined by using Open Street Map internet site (https://www. openstreetmap. org/\#map=6/39. 031/35. 252). Finally, an automatic axial map of Elazığ was created with the DepthMapX program.

The integrated space syntax theory can extend the capabilities of GIS for modeling spatial objects (Jiang, Claramunt and Klarqvist, 2000, p.161). There is also some other software that can be used for practicing space syntax analysis. Axwoman, Seyntax2D, Pesh, SpaceBox, NetBox, NewWave, Ovation, WebMap, Mindwalk, Place Syntax, Ajax, Confeego, and Depthmap (Atak, 2009, p.19-23-57) are some of these tools. Most of this software hasn't been currently used while some of them such as Confeego, Syntax2D, Axwoman, are integrated into other GIS programs as they are compatible with older versions.

DepthMap is the currently most frequently used program for Space Syntax Analysis. Each program analyzed in the scope of this study has different features; the DepthMap program involves all these features in addition to the advantage that it enables automatic drawing. This is why, DepthMapX, the latest version of the program, is preferred in this study. Divided roads were drawn in the shape of two lines as inbound and outbound routes as the divided roads are mostly used in highways, which are mostly used by cars rather than walkers. Cars that use divided roads don't move according to sight, they mostly follow signs; this is why, divided roads were drawn as two-way, inbound, and outbound routes. The parts of the roads vertically cut by walkers (crosswalks on highways 
used by walkers) were included in the system in the manual drawing. The same is applied in RCL and Automatic Drawing techniques.

These three methods are discussed in terms of the time for creating axes, textural similarities, and similarities in the scope of the analysis results of this study.

\section{ANALYSIS OF AXIAL MAP CREATION METHODS}

Three main axial map creation methods will be analyzed in this study. These are manual axial maps, automatically drawn (with programs) axial maps, and Road Centre Line data.

\section{Manual Drawing Method;}

Axial lines have been widely used for the urban morphological study with the space syntax theory (Sun, 2013, p.13). The axial map is an alternative representation of urban networks to measure the level of accessibility which is defined as "spatial integration" (Klarqvist,1993, p.11). Over the last 30 years, this street network representation is the one that space syntax analysis and research have been built upon; it is the fundamental premise of space syntax theory. It is seen that this analysis method functions as the spatial unit through which the interaction of society and space can be observed and understood. Hand-drawing is generally used in creating the axial map. The process of over-laying raster image maps is used to complete the process; following that step, the user draws the lines that represent the longest accessible and visible point (this process was completed by using tracing paper overlaid on a paper map with the axial line model in the early years, due to the lack of processing power; after this step, the image is scanned and redrawn in the computer) (Dhanani et al, 2012, p.7).

"Axial map" is a whole set of intersecting lines through all the spaces of an urban grid. An axial map is the minimum set of axial lines that pass through each convex space (Turner, Penn, Hillier, 2005 p.426; Liu, Jiang, 2011, p.2). The use of an algorithm in axial maps is described as: "The first step is to determine the longest axial line (the longest visibility line). The second step is to determine the second-longest axial line and these two steps are repeated until the whole space is covered with intersecting axial lines" (Jiang, Claramunt, 2002, p.297).

An axial map is drawn on a separate layer as an overlay from a chosen base map. This map consists of the longest and shortest lines. There a few rules to consider for the manual drawing procedure:

- Start with the longest and finish with the shortest line,

- Avoid "overmodeling" that can influence the results,

- The fewest possible lines should be drawn; there should be no repetition of axial lines,

- All convex space should be crossed and all rings in the system made,

- Make sure you do not stop an axial line before it connects to another one. 
It also has to be remembered that lines have to stop if they reach an obstacle or impermeable objects like a facade or wall. If a line cuts through a building or interferes with another axial line on the neck of an object, then it is simply wrong and will influence the analytical result (Czerkauer-Yamu, 2010, p. 21).

The manual drawing of the study field was carried out by a single person based on satellite images. The drawing was completed in approximately eight months. This time can be longer or shorter depending on the areas of urban spaces. Besides, the number of people drawing an area is a variable that affects time.

Although manual drawing rules are specifically mentioned, drawing a study field by a single person is mostly more correct; different individuals may perceive space differently which may cause incorrect results in a system.

\section{RCL Method;}

This method can be implemented in two ways; the first method is Open Street Map created by voluntary users (Graham, 2010, p.428) Open Street Map provides the voluntarily distributed geographic data (Haklay, Weber, 2008, p.13) and the second method is National Mapping Agency Road Network Data, which is also called Integrated Transport Network (ITN). In general, official RCL data can be obtained from different sources such as region, city, and national data repositories or private companies such as and Google or Tom Tom. These data are not open for free public use with a few exceptions (e.g. the ITN dataset in the UK or TIGER in the US) (Pezzica et al, 2019, p.4).

Today, Open Street Map is the most popular VGI service in the world and provides coverage across all continents (Jiang, 2013, p.125). The street network component of the OSM VGI data is created and supplied through Road Center Line format. The data can be downloaded through web portals where the public, can obtain an area's, country's, or continent's specific datasets at no cost (see: http:// download. geofabrik. de/osm/andhttp://downloads. cloudmade. com/) (Dhanani et al, 2012, p.4). Unlike the VGI data, ITN isn't free; it costs $£ 400-500$ (600-750 USD) per square kilometer. This price, unfortunately, puts it out of reach of many commercial entities (in the academic realm data are often supplied free of charge); the entities which aren't prepared to make the initial investment without clear beneficial financial reasons are usually unwilling to try to pay the price. An important difference between the VGI and the ITN data is that it is possible to record all of the road features in the ITN dataset (Dhanani et al, 2012, p.6).

Open Street Map data are used in the study. A series of arrangements are made and simplifications are conducted according to the DouglasPeucker algorithm. Generalization, among cartographers, is known as the process of simplifying geographic data in order to produce a map at a certain scale in a readable way. This process contains using different techniques to achieve a required geometric simplification in data 
representation. The Douglas-Peucker algorithm, one of the most popular generalization algorithms, uses an iterative fit procedure to reduce the complexity of a curve that is composed of numerous line segments and replaces it with a similar one with fewer points. This algorithm functions at different intensities; it modifies the initial geometry according to a given tolerance value corresponding to the required level of simplification (Pezzica at all., p.11). The basic rules of these simplifications are presented below:

1. Roundabouts: They are simplified with straight links between consecutive entries or exits to the roundabout. Roundabouts that involve buildings at the center can be treated like urban blocks.

2. Staggered junctions: It is possible to draw a diagonal line when two almost parallel lines can be approached by a slight change in the movement direction.

3. Squares: Connections are drawn between all "entrance" and "exit" points in a square. A straight link is drawn in between two points that are directly visible and accessible. The cartographer should attempt to draw the minimum number of lines with all possible connections.

4. Underpasses, overpasses, and bridges: This rule is the easiest to implement because RCL map lines cross but not intersect where there is a difference in level; so, the only requirement is that no unlinks layer is loaded and that the RCL map is directly converted to a segment map.

5. Parallel lanes: Different lines that are typically found in motorways and highways are represented by two parallel lines İn an RCL map. An axial map is not directional; in this map, parallel lines are drawn as single medial lines (Kolovou et al. 2017, p.5).

\section{Automatic Creation of the Axial Map}

Axial maps can be automatically formed as an alternative to manual drawing. It is possible to create these maps with the DepthmapX program. Automatic drawing can be chosen by clicking on the sign showing four axial lines in the Depth MapX program. After the automatic drawing is completed, an image showing the space full of lines is formed. These lines can be minimized by the program and the drawing can thus be completed (Al_Sayed, 2018, p.23-24).

This method is mostly used for enclosed spaces; however, it is also possible to use it for urban spaces. To implement this method for these spaces, it is necessary to regard the whole urban space as an enclosed area. The methodological steps to be followed in this process are explained below:

Firstly, a master plan of the target space should be obtained. As the scales of master plans are smaller, there are fewer details. On the other hand, as master plans present the current state, mapping the current state of space and other practices are carried out based on them (Canpolat, 2019, p.569). Lots of current settlements in a city are shown in the obtained plan. The first important issue to be taken into consideration is that lots are drawn in the shapes of polygons. 
The periphery of the study field should be drawn as a poly-line and space should be transformed into an enclosed space. The computer creates lines in the empty spaces among enclosed polygons in an automatic drawing program; it regards poly-lines as the periphery of the space and stops drawing according to these lines.

The first lines consist of thousands of lines, and it is possible to minimize them through the program. They are minimized with the Fewest Line Map tool for the study and analyses are carried out based on them.

\section{COMPARISON RESULTS}

\section{Temporal Comparison}

Among the methods analyzed in this study, manual drawing took the longest time; the user spent almost eight months manually draw the study field. Axes that were drawn using satellite images were controlled by making observations in the real field and the accuracy tests were carried out.

RCL map, on the other hand, can be created by using an internet site. Checking the accuracy of junction points and adding nodes to the roads such as bridges, viaducts, and subways take the longest time in this process. There are also some other necessities of the system; simplification of RCL is the most important one of them. In their study, Kolovouet al. simplified the RCL map by using the Douglas-Peucker Algorithm (2017, p.10). Douglas-Peuckerproved that their generalization method makes a better proxy of the human cognitive wayfinding behavior regarding human perception and how a person perceives space as continuous. In their study, Kolovou et al. mention that the obtained analysis results are more accurate than the non-simplified maps. They could complete this simplification by using the extension of the QGIS program.

Simplification depends on decreasing the nodes on axial maps according to a specific algorithm and axial edging. Thus, it is possible to bring these axes closer to the manually drawn axes. Simplification units used in the algorithm are determined by the user through the trial method and the unit closest to the manual drawing is preferred for analysis. In this context, the RCL map of Elazı ğ was simplified by the MapInfo program. The algorithm used in the simplification process was $200 \mathrm{~m}$; namely, nodes were automatically cleared at every $200 \mathrm{~m}$ and it was determined that this method was closest to the texture in manual drawing (Figure1). On the other hand, it should be noted that the use of RCLs in Turkey may sometimes cause some errors. On the other hand, spaces with controlled access may involve the biggest errors. The University, military zone, official agencies and the field of cement factory are restricted zones in this study field. These specific places aren't used by the general public; on the other hand, students and individuals who work in the university can enter the university area while entrances to the other specific areas are controlled. However, the road systems of these places are involved in the 
RCL map. In addition to this, routes in these areas can be seen in the system (Figure2).

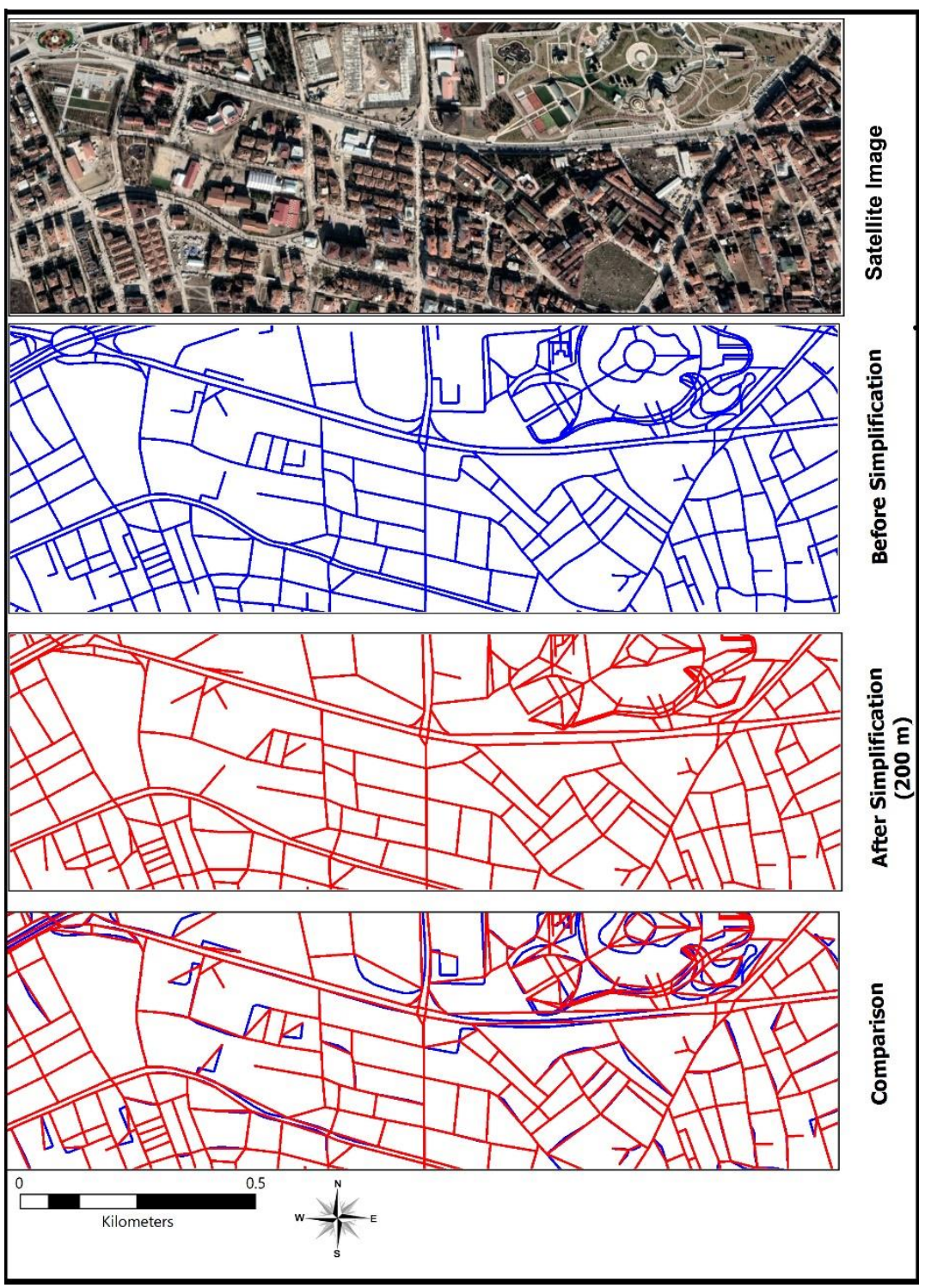

In this respect, it is necessary to specifically determine intersections, roads or subways and the lines that don't intersect with one another in RCL maps. Removing the axes in universities, official agencies, military zone, or areas of factories is a key requirement. Finally, it is necessary to simplify RCLs. Based on these processes, the period necessary for preparing an RCL map for analysis is approximately one week.

An automatic drawing of an axial map requires the construction plan as mentioned before. It is necessary to analyze lot and parcel polygons in construction plans and turn lot parcels drawn with lines into polygons. After that, the construction plan should be turned into an enclosed space as a whole. The creation of an axial map with the Depth Map program starts after this transformation; this process varies depending on the size of the study field. The automatic axial map transformation for Elazığ was completed in approximately 6 hours by the computer. These types of
Figure 1. The Result of RCL Simplification 
completed maps are named All Line Map by the program and they consist of millions of lines. These lines are minimized by the program, Fewest Line Map is created and the analysis step starts. Nodes should be added to roads such as subways, viaducts, etc. at this step, just like RCL. After that process, any kind of possible overlaps should be determined and cleared; it can take approximately one week to complete this process depending on the size of the space.

\section{Textural Comparison}

Textures of the basic three Axial Map creation methods based on the study field will be comparatively analyzed in this section of the study. After this step, textures of intersections and squares will be analyzed. Finally, the number of lines in axial maps, and the specific places of the longest lines will be evaluated.

In terms of the comparison of axial maps in study fields, it is possible to say that the texture closest to the manual drawing is generally created by the automatic drawing. Lines in RCL maps, on the other hand, are denser when compared to the other drawing methods (Figure2).

The textural similarity on a lower scale was analyzed based on Hazardağlı intersection in the study. It can be said that the textures in each of the three techniques are similar. However, lines in manual drawing and RCL are structurally more ordered and similar to each other in terms of form (Figure3).

Two different square areas were evaluated in this study. The first of these areas is Kültür Park, which consists of paths only available for walkers. Artificial pools around the paths interrupt transportation. In the automatic drawing technique, the whole area of Kültür Park is considered an empty square; this is why a different textural form is created in this method. However, it shouldn't be thought that this situation is a deficiency of the automatic drawing method. If artificial pools that interrupt connections were entered as enclosed spaces into the system, it would be possible to see shapes that are similar to the ones in manual and RCL methods. As the specific structure of them is taken into consideration in manual and RCL methods, they are more similar in terms of texture (Figure3).

Post Office Square is chosen as the second area to test the axial map drawing behaviors in homogenous spaces. This square can be regarded as a completely homogenous space. At the end of the practices, it is determined that the textures of each of the three methods were different from one another. The area of the square is empty in RCL lines while there are two intersecting lines in the north-south direction in the automatic drawing. On the other hand, lines designed according to the manual drawing technique are texturally completely different from the other drawing methods (Figure3).

When the axial map drawing methods are analyzed in terms of the number of lines and similarities on the longest line, it can be said that the number of lines in the manual drawing is close to the number of lines in 
the automatic technique. However, lines in RCL are considerably higher than that of the other two methods (Table 1).
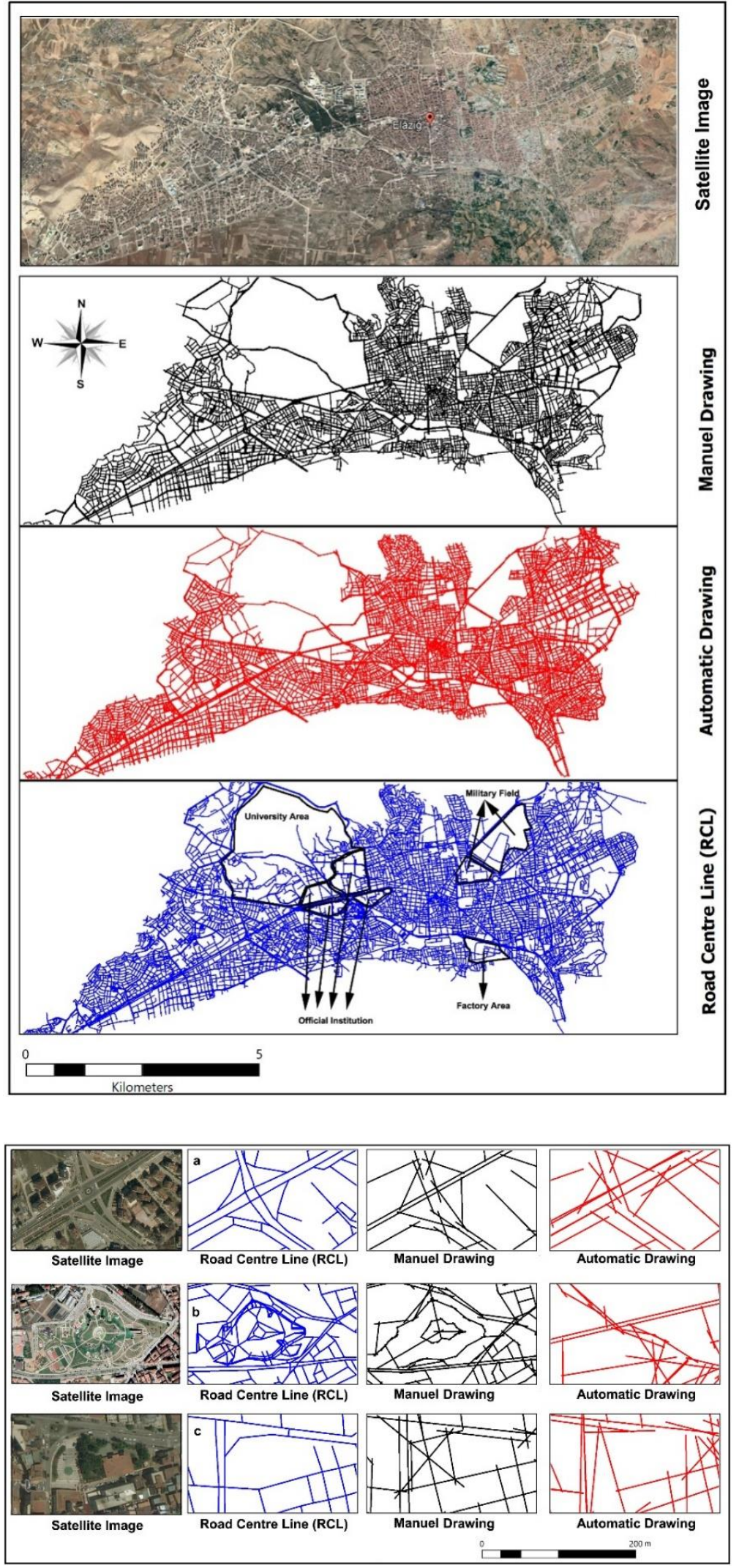

Figure 2. Textural Comparison of Maps

Figure 3. a) Hazar Dağlı Intersection b) Kültür Park Squares c) Post Office Squares 
Table 1: Line Numbers and Lengths of Drawing Techniques in the Study Area

\begin{tabular}{|l|c|c|}
\hline Drawing Techniques & Number of Lines & Longest Line (Km) \\
\hline Manual Drawing & 5.093 & 6.56 \\
\hline Automatic Drawing & 4.705 & 6.45 \\
\hline Road Centre Line (RCL) & 14.698 & 1.65 \\
\hline
\end{tabular}

Kolovou et al., (2017) used the Douglas-Peucker algorithm to transform RCL maps into axial maps. The basic purpose of the algorithm is to minimize the over-fragmentation of continuous space in a drawing method by decreasing the number of nodes in a system (Kolovou et al., 2017; p.8). A similar technique was conducted to Elazığ RCL map for this purpose. The "snap/thin" tool of the MapInfo program was used and the number of nodes in the study field was decreased according to the $200 \mathrm{~m}$ algorithm. While the number of nodes in the RCL map before simplification was 39.815, it was decreased to 29.595 after simplification. Although it is possible to minimize the number of nodes, computers regard space between every node as a free road in RCL lines. The Road Center Line map has many more segments than the axial map. The total segment length of the Road Center Line map is shorter than the axial map, as the axial lines overhang the ends of roads (Turner, 2007, p.548). The number of lines in RCL is thus higher than that of the other methods. Because of the very same reason, while the longest route in the manual and automatic drawing is Elazığ-Malatya road, the longest route is Alparslan Türkeș Boulevard on the RCL map.

\section{Comparison of Space Syntax Analysis Results}

The change from Axial into Line-segment maps is one of the most important developments in Space Syntax analysis, both theoretically and methodologically (Hillier and Iida,2005; Hillier,1999a,1999b; 1; Steadman,2004; Dalton, 2001). Another significant development is the use of the Road Center Line for urban analysis.

The Angular Segment Analysis (ASA) has become the main alternative to the Axial map analysis and it is commonly used by Space Syntax researchers. The analysis is based on using a Line-segment map, generated either from an Axial map or from a Road-centre-line map (Stavroulaki et al., 2017, p.5). As the Road Center Line data used in this study represent vehicular networks, the quantitative analysis is constrained to vehicular road usage, although the methodology could be expanded to pedestrian networks (Turner, 2007, p.541).

The axial analysis depends on the calculation of the number of road connections in a given system; it thus makes a depth analysis of all the streets and main roads in the system and puts them into hierarchical order. In Angular Segment Analysis, the return angle of the streets and main roads are taken into consideration, and calculations are accordingly made. 
The first calculation in this context is Integration calculation. Radius, which is represented with $R$, is calculated as the first step of this calculation process. Radius allows the classification of the global structure of the depth in any chosen depth statue. It is generally systemized in local and global measurements. Radius 3 analysis (different numbers can be used) is used for local measurements while Radius $\mathrm{N}$ analysis (Radius Infinity) is used for global measurements. In other words, Radius 3 enables us to understand the regional system while Radius $\mathrm{N}$ emphasizes centralization in an urban structure (CzerkauerYamu, 2010:18)".
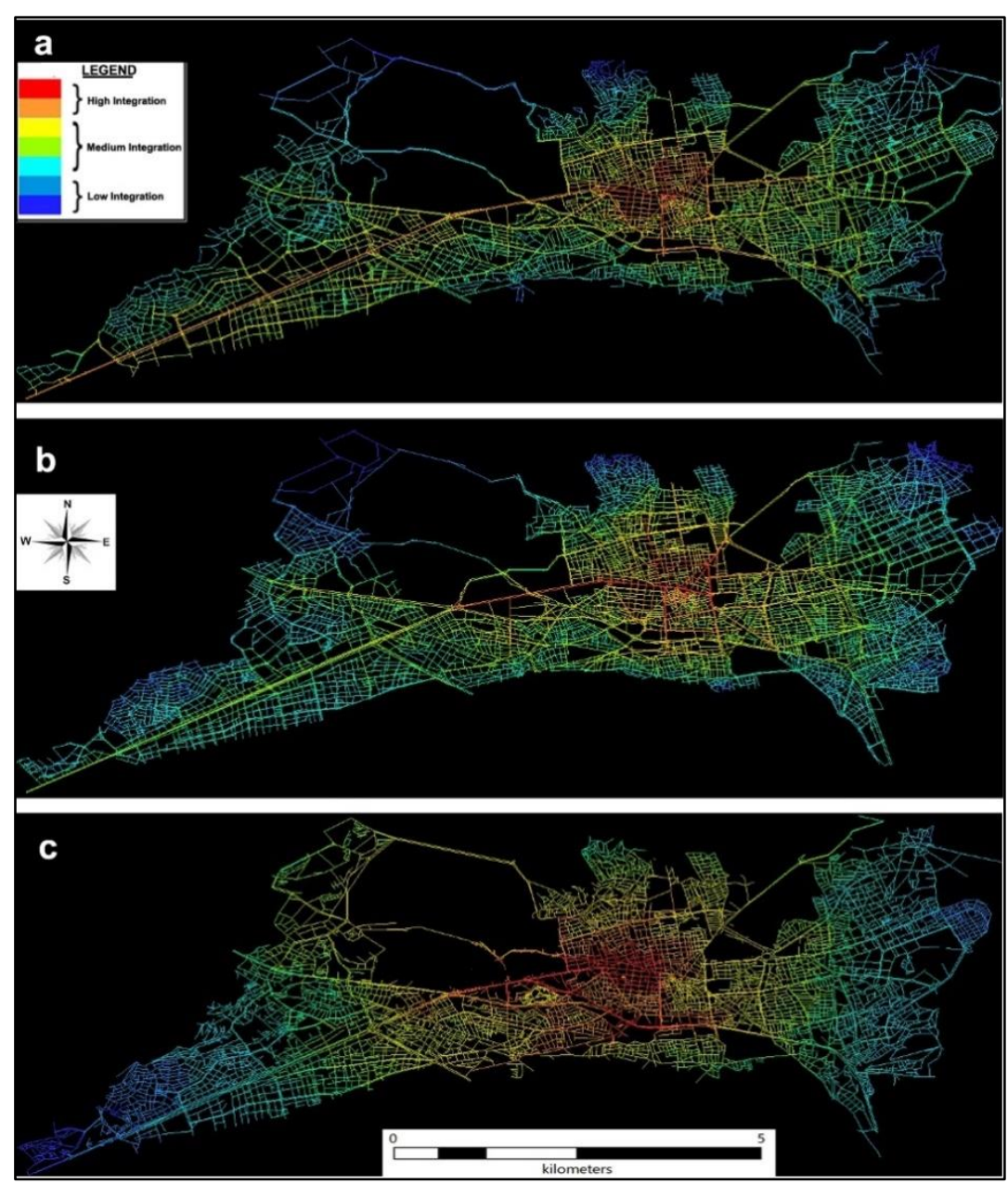

Figure 4. Axial Rn Analysis a) Manual Drawing b) Automatic Drawing c) Road Center Line

Manual, automatic drawing, and RCL maps will be analyzed with Axial and Angular Segment analysis methods and results will be compared in this section of this study. Integration values are the only ones taken into consideration in these comparisons. Axial and angular segment analyses are firstly calculated on global and local scales. Rn value is measured on a global scale in axial analyses while R15 is measured on a local scale. Rn value is measured in Angular Segment analysis on a global scale while $\mathrm{R} 400 \mathrm{~m}$ value is preferred on the local scale. More than one $\mathrm{R}$ analysis is completed while calculating the local measurements in the study field. 
However, R15 and R400 values are preferred as they are proper for the study field's radius and they give the most real-like result.

RCL maps do not statistically yield correct results in axial analyses, but this analysis is conducted to determine the behavior of RCL maps in axial analyses.

It can be said that manual drawing gives the best results based on field observations when it is compared with Axial Rn analysis. According to the results, automatic drawing results are closest to the manual drawing results. On the other hand, while the results of RCL maps are the same as the other methods in the main routes of the study field, the results of them in access points are incorrect (Figure4).
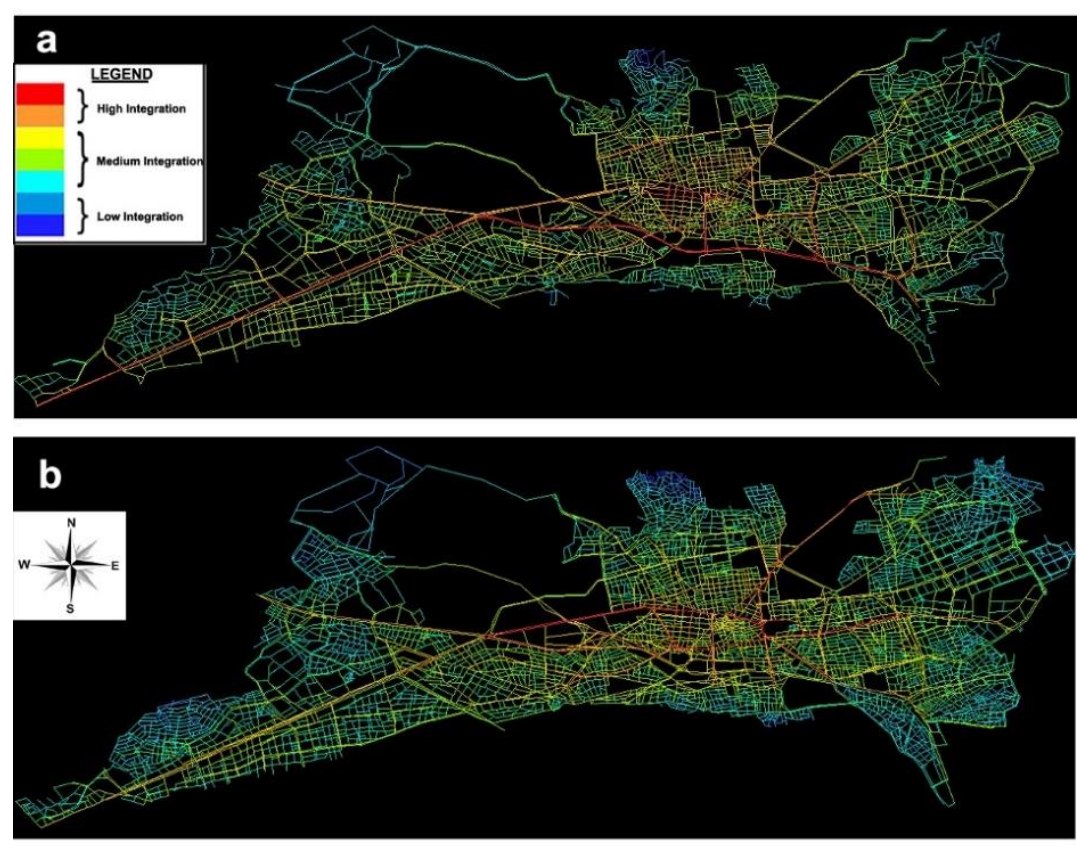

Figure 5. Angular Segment Rn Analysis a) Manual Drawing b) Automatic Drawing c) Road Center Line

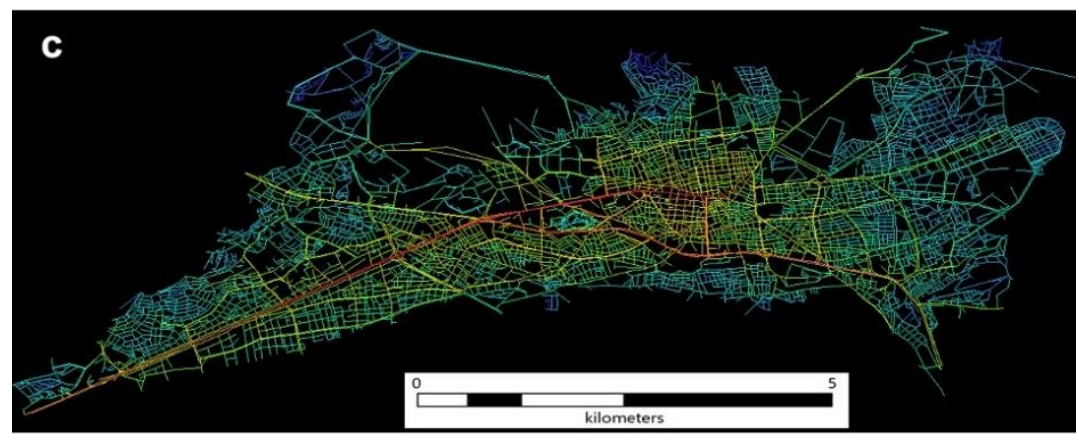

It is observed that there is a total decrease in the integration value of the city in the Angular Segment Rn analysis when compared to Axial Rn analysis. When a more detailed analysis of the issue is conducted, it is possible to see that result obtained from manual drawing is almost the same as the result of the RCL map. Angular Segment analysis mostly showed highways. The map obtained by the automatic drawing method is different. The result of this method is the same as the result of the axial analysis, which indicates consistency. It is possible to say that automatic 
drawing gave more accurate results; the lines with high integration values are the areas frequently used by walkers and automobiles (Figure5).
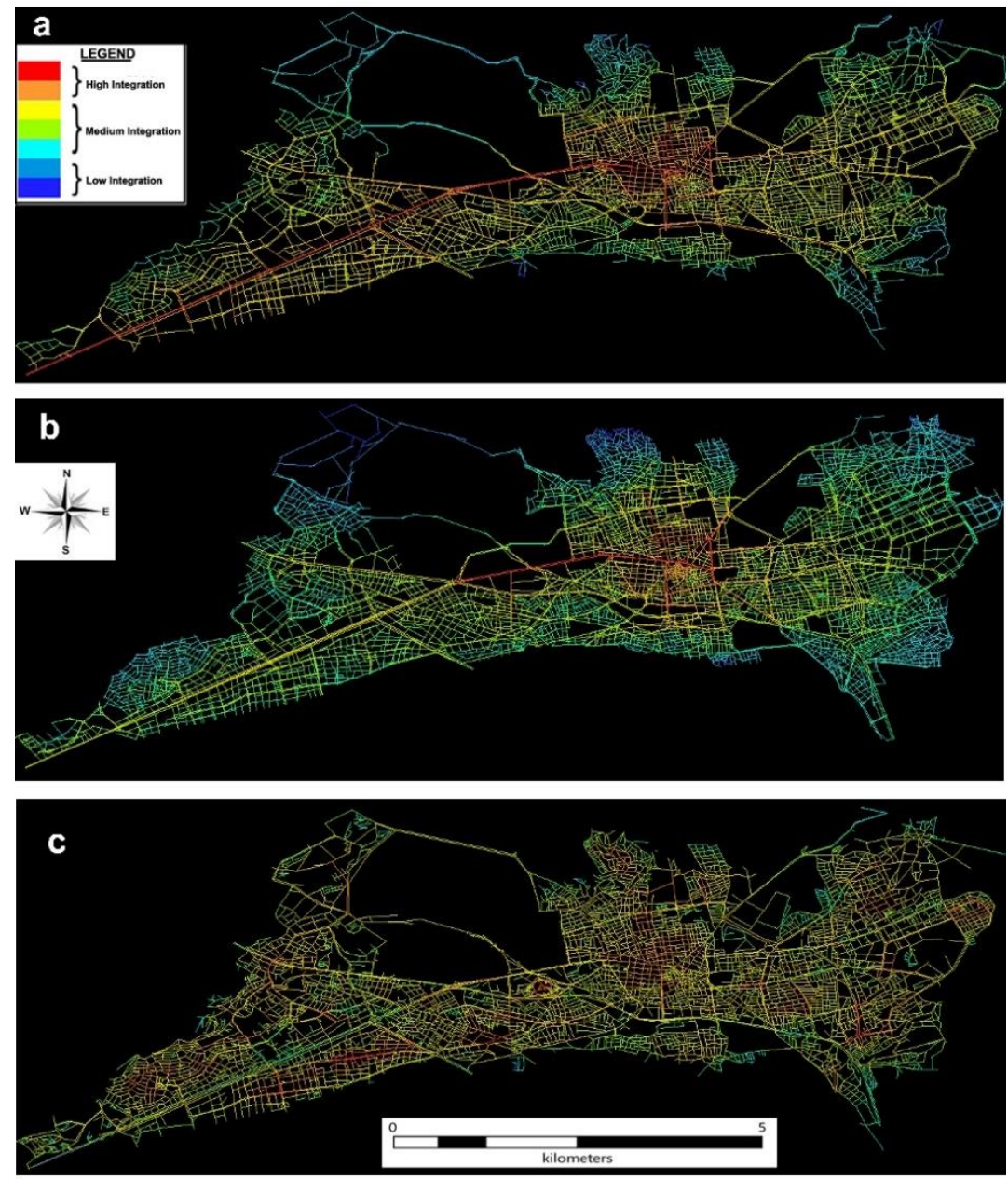

Manual and automatic drawing results are similar in Axial R15 local analysis while RCL map results in the local analysis are completely different and far from the real values. As mentioned before, the RCL map isn't expected to yield correct results because of the very system of it. Despite the similarity between manual and automatic drawing, the most accurate result is that of manual drawing. The difference between manual and automatic drawings is obvious especially in the integration of streets and roads at the center of the city (Figure6).

Angular Segment R400m local analysis results of the three methods are similar (Figure7). On the other hand, when a more detailed analysis is conducted, it is observed that manual drawing and RCL results are more similar. This similarity is based on the higher integration values of these methods. The results obtained from the automatic drawing are, in a sense, the average of the other two methods. Routes represented with brown and orange in the central areas of the city are represented mostly with orange and yellow in the RCL map. The western and southern line of the city is represented with yellow in Automatic drawing, while that line is
Figure 6. Axial R15 Analysis a) Manual Drawing b) Automatic Drawing c) Road Center Line 
red in manual and RCL maps; this is the biggest difference of automatic drawing.
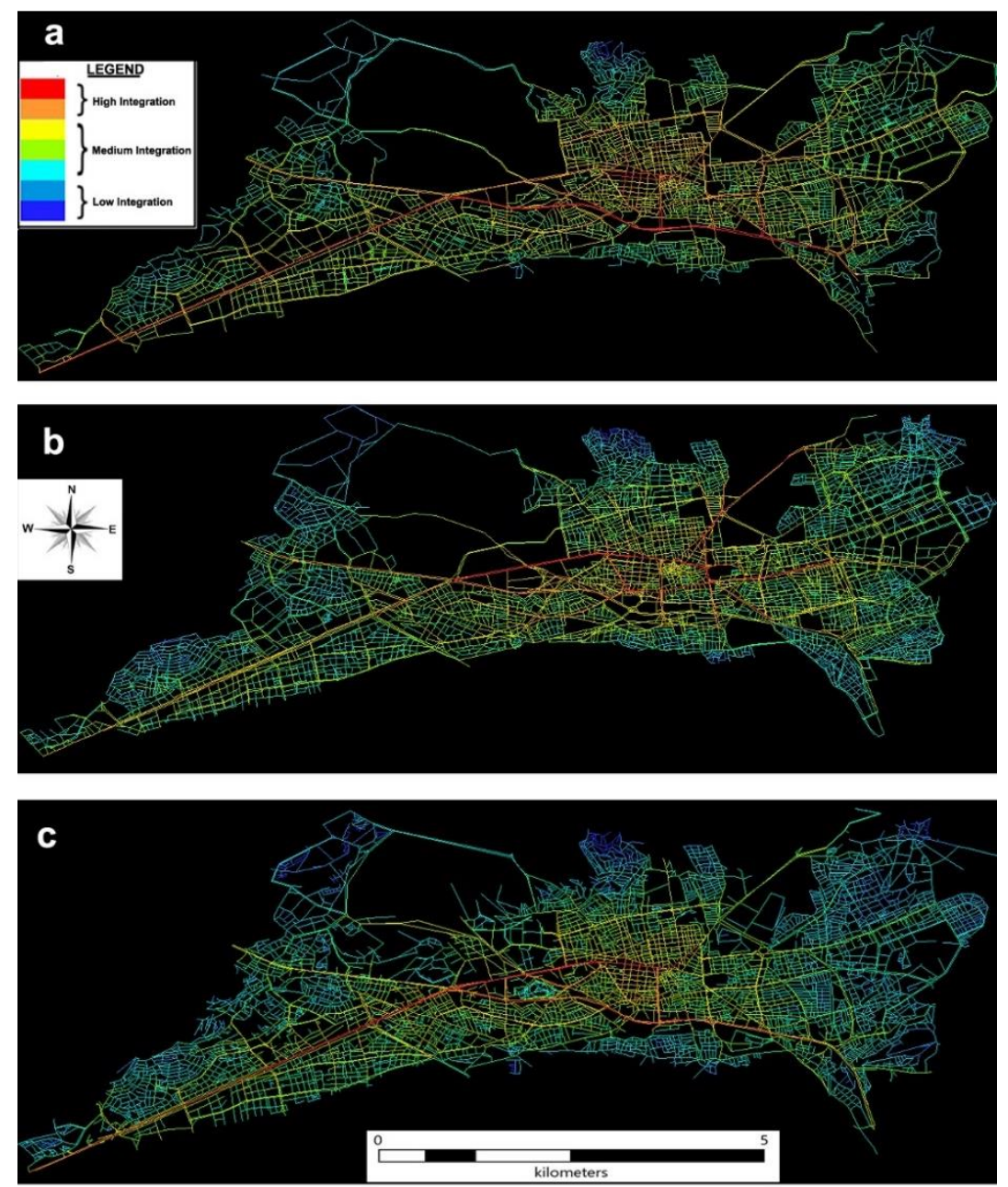

\section{RESULT AND EVALUATION}

Manual Drawing, Automatic Drawing, and RCL maps are three different axial map creation techniques of the Space Syntax analysis. However, the use of RCL maps or Automatic Drawing has been more frequently preferred today as they diminish the drawing differences by different users and they give the chance to analyze wide spaces. There are many computer software developed for the Space Syntax method in the past. Axwoman, Seyntax2D, Pesh, SpaceBox, NetBox, NewWave, Ovation, WebMap, Mindwalk, Place Syntax, Ajax, Confeego, and Depthmap are some of these tools. Most of this software hasn't been currently used while some of them such as Confeego, Syntax2D, Axwoman, are integrated into other GIS programs as they are compatible with older versions.

Some additional processes are inevitable for automatic drawing and RCL maps. For instance, simplification of RCL maps, organization of curves in intersections, adding squares according to the drawing techniques, determining restricted zones, and eliminating them are some of these 
necessary steps. Also, three basic operations can be performed on the original RCL maps. These are filtering generalization and re-modeling. filtering is the process of separating the roads on the original RCL maps by type (pedestrian, car, bicycle road, etc.). The method of generalization is another technique used in the literature to simplify OSM data. Cartographers define generalization as the process of simplifying geographic data to produce a readable map at a certain scale. This type of process involves using various techniques to achieve a required geometric simplification in data representation. The last operation step that can be done is Re-Modeling, which refers to the strategy of locally modifying the original graph, manually or automatically, in order to produce a model more coherent with a preferred interpretation of reality. The remodeling includes the arrangement of traffic islands, artificial dead-end streets, roundabouts, junctions, and roundabout mainline connections and parallel streets.

Although Fewest Line is practiced in automatic drawings, it may be necessary to determine the overlapping lines and organize the squares according to the drawing technique, that is, it is believed that both of the methods should be technically improved.

The manual drawing method is the longest procedure while the RCL method is the shortest; automatic drawing, on the other hand, consumes different times in different applications. If the polygons used in the automatic drawing method are proper, the method gives results as fast as RCL maps. If it is not created with a method suitable for automatic drawing techniques, the process takes a longer time. Lot and blocks should be drawn in parcels to be more practical; unfortunately, these lots are sometimes drawn in Polylines instead of Polygons. In such cases, it is not possible to automatically create an axial map; manual drawing is more reasonable in such processes.

As mentioned before, manual drawing is the basic method of Space Syntax. Automatic drawing enables drawing axes according to the methodological viewpoint and including pavements that ensure coherence in the system. Automatic drawing is the technique that is closest to the traditional one in terms of texture. RCL maps undergo a process of simplification to obtain the best results; a similarity between RCL maps and manual drawing texture can be ensured through some additional processes. Lines in RCL maps cannot be in coherence with the traditional technique despite these processes.

Textural similarity among all three techniques in terms of intersections in the study field increases after RCL simplification. However, manually and automatically drawn shapes are texturally most similar. RCL and Automatic Drawing techniques failed in reflecting the texture of squares. It is believed that some manual interventions after completing drawings are inevitable.

Manual drawing is the most successful method in axial analysis, on global and local scales. The automatic drawing method gave the closest results to manual drawing according to the results of both analyses. 
Although RCL and Manual drawing results are similar in Angular Segment $\mathrm{Rn}$ analysis, the most coherent and reliable result was obtained from the automatic drawing. RCL map analysis gave the most accurate result in terms of R400m analysis in the same system.

As a result, it can be said that each technique has some advantages and disadvantages. Analyses are carefully and objectively evaluated and methods that yield the most accurate results based on the field observation are determined in this study. Deciding on the use of a method solely based on these analyses wouldn't be a scientifically proper approach, namely, evaluation and decision making processes should be carried out by the users and readers.

\section{CONFLICT OF INTEREST}

No conflict of interest was declared by the authors.

\section{FINANCIAL DISCLOSURE}

The authors declared that this study has received no financial support.

\section{ETHICS COMMITTEE APPROVAL}

Ethics committee approval was not required for this article.

\section{LEGAL PUBLIC/PRIVATE PERMISSIONS}

This study did not require any special permission.

\section{REFERENCES}

Al_Sayed K. (2018). Space Syntax Methodology, Bartlett School of Architecture, UCL.

Atak, Ö. (2009). Mekan Dizim ve Görünür Alan bağlamında Geleneksel Kayseri Evleri. (Unpublished master's thesis). İTÜ Fen Bilimleri Enstitüsü, İstanbul.

Canpolat F. A. (2019). İmarPlanlarınınKentselAraştırmalardaKullanımı, II. Uluslararası Sosyal Bilimler ve İnovasyon Kongresi, Bildiriler Kitabı, 2627 Nisan 2019, Elazı ğ.

Czerkauer-Yamu, C. (2010). Space Syntax Understanding, Hiller's Concept of a Spatial Configuration and Space Syntax Analysis, Unıversite de Franche-Comte, Unıversity College London, İngiltere.

Çil,E.(2006). Bir Kent Okuma Aracı Olarak Mekan Dizim Analizinin Kuramsal ve Yöntemsel Tartışması, MEGARON, YTÜ mim. Fak. E-Dergisi, Cilt 1, Sayı,4, s. 218-233, İzmir.

Çil, E. (2008). Kula Tarihsel Kentinin Yirminci Yüzyıldaki Fiziksel Dönüşümünün Mekan Dizim Analiziyle İncelenmesi, Gazi Üniv. Müh. Mim. Fak. Dergisi, Cilt: 23, No: 2, s. 283-293, Ankara.

Dalton, N. S. (2001). Fractional configuration analysis and a solution to the Manhattan problem, In Peponis,J., Wineman, J., Bafna, S. (eds.), Proceedings of the 3rd International Space Syntax Symposium, Atlanta, U.S.A.: Georgia Institute of Technology, p.26.1-26.13klay

Dhanani A., Vaughan L., Ellul C., Griffiths S. (2012). From the axial line to the walked line: evaluating the utility of commercial and user-generated 
street network datasets in space syntax analysis, Eighth International Space Syntax Symposium, p.8211: 1-32, Santiago de Chile.

Graham, M. (2010). Neogeography and the palimpsests of placeWeb 2.0 and The Construction of Avirtual Earth. Tijdschriftvoor Economischeen Sociale Geografie, 101(4), 422-436.

Haklay, M., Weber, P. (2008). Open Street Map: user-generated street maps. Pervasive Computing, IEEE, 7(4), 12-18.

Hillier, B., and Iida, S. (2005). Network effects and psychological effects: A theory of urban movement, In Van Nes, A. (ed.), Proceedings of the 5th International Symposium on Space Syntax, Delft: University of Technology Vol.1, p.553-564.

Hillier, B. (1999a). Centrality as a process: accounting for attraction inequalities in deformed grids', In Urban Design International, vol. 4, p. 107-127.

Hillier, B. (1999b). The hidden geometry of deformed grids: Or, why space syntax works, when it looks as though it shouldn't, In Environment and Planning B: Planning \& Design, Vol. 26, p.169-191.

Jiang, B. (2013). Volunteered geographic information and computational geography: new perspectives, in Sui, D., Elwood, S. \& Goodchild, M. (eds.), Volunteered Geographic Information in Perspective, Springer: Berlin, 125138.

Jiang, B., Claramunt, C.,Klarqvist, B. (2000). An integration of space syntax into GIS for modelling urban spaces. International Journal of Applied Earth Observation and Geoinformation, 2, 161-171.

Jiang, B., Claramunt, C. (2002). Integration of Space Syntax into GIS: New Perspectives for Urban Morphology, Transactions in GIS, Cilt: 6, Sayl: 3, s. 295-309, USA.

Klarqvist, B. (1993).A Space Syntax Glossary, Nordisk Arkitekturfoskning, 2th Edition, Norway.

Kolovou I., Gil J., Karimi K., Law S., Versluis L. (2017). Road Centre Line Simplification Principles For Angular Segment Analysis, Proceedings of the 11th Space Syntax Symposium, Chapter 165: p.1-16, Lisbon.

Long, Y., Baran, P. K., Moore, R. (2007). The role of space syntax in spatial cognition: evidence from urban China. Processing of 6th International Space Syntax Symposium, Chapter 129: p.1-6, Istanbul.

Liu, X., Jiang, B. (2011). Defining and Generating Axial Lines from Street Center Lines for better Understanding of Urban Morphologies, Preprint, arxiv. org/abs/1009,5249.

Omer I., Kaplan N., Jiang B. (2017). Why Angular Centralities Are More Suitable For Space Syntax Modeling? ,Proceedings of the 11th Space Syntax Symposium, Chapter 100: p.1-12, Lisbon.

Özkan Özbek, M. (2007). Fizik Mekan KurgularınınSosyal İlişkiler Üzerinden Arnavutköy Yerleşimi Bütününde Mekan Dizimi (Space Syntax) Yöntemi İle İncelenmesi, Mimar Sinan Güzel Sanatlar Üniversitesi, Fen Bilimleri Enstitüsü, Şehircilik Ana Bilim Dall, DoktoraTezi, İstanbul.

Pezicca C., Cutini V., Bleıl De Souza C. (2019), Rapid Configurational Analysis Using Osm Data:Towards the use of Space Syntax to orient post- 
disaster decision making. Proceedings of the 12th Space Syntax Symposium, Chapter 147: p.1-18, China.

Stavroulakl G., Marcus L., Pont M. B., Nilsson L. C. S. (2017). Representations of Street Networks in Space Syntax: Towards Flexible Maps and Multiple Graphs, Proceedings of the 11th Space Syntax Symposium, Chapter 175: p.1-16, Lisbon.

Steadman P. (2004). Developments in space syntax, In Environment and Planning B: Planning and Design, Vol31, p.483- 486.

Sun X. (2013). Comparative Analysis of Urban Morphology: Evaluating Space Syntax and Traditional Morphological Methods, Faculty of Engineering and Sustainable Development, Department of Industrial Development, IT and Land Management, Degree project thesis, Master, Gavle, Sweden.

Turner A., Penn A. İ., Hillier B. (2005). An Algorithmic Definition Of The Axial Map, Environment and Planning B: Planning and Design, volume 32, pages 425-444.

Turner, A. (2007). From axial to Road Center Line: A new representation for Space Syntax and a new model of route choice for transport network analysis. Environment and Planning B: Planning and Design, volume 34(3):539-555.

\section{Resume}

Emrah Şikoğlu (PhD) is currently working as an assistant professor at FU Faculty of Humanities and Social Sciences, Geography Department. His researches mainly focus on Urbanization, Space Syntax, GiS and Behavioural Geography. 